\title{
Global patterns in mangrove soil carbon stocks and losses
}

Authors: Trisha B. Atwood ${ }^{1,2 *}$, Rod M. Connolly ${ }^{3}$, Hanan Almahasheer ${ }^{4,5}$, Paul Carnell ${ }^{6}$, Carlos M. Duarte ${ }^{4}$, Carolyn Ewers ${ }^{6}$, Xabier Irigoien ${ }^{7}$, Jeffrey Kelleway ${ }^{8}$, Paul S. Lavery ${ }^{9,14}$, Peter I. Macreadie ${ }^{6}$, Oscar Serrano, ${ }^{, 9,10,14}$, Christian Sanders ${ }^{11}$, Isaac Santos ${ }^{11}$, Andrew Steven $^{12}$, Catherine E. Lovelock ${ }^{1,13}$

${ }^{1}$ Global Change Institute, University of Queensland, St. Lucia, QLD, Australia

${ }^{2}$ Department of Watershed Sciences and Ecology Center, Utah State University, Logan, UT, USA

${ }^{3}$ Australian Rivers Institute - Coast and Estuaries, School of Environment, Griffith University, Gold Coast, QLD, Australia

${ }^{4}$ King Abdullah University of Science and Technology (KAUST), Red Sea Research Center (RSRC), Thuwal, 23955-6900, Saudi Arabia

${ }^{5}$ Biology Department, University of Dammam (UOD), Dammam 31441-1982, Saudi Arabia.

${ }^{6}$ Centre for Integrative Ecology, School of Life and Environmental Sciences, Faculty of Science Engineering and Built Environment, Deakin University, VIC, Australia

${ }^{7}$ AZTI Tecnalia, Herrera Kaia, Portualdea z/g, 20110 Pasaia, Spain

${ }^{8}$ School of the Environment, University of Technology Sydney, NSW, Australia

${ }^{9}$ School of Science \& Centre for Marine Ecosystems Research, Edith Cowan University, Joondalup Drive, Joondalup WA 6027, Australia

${ }^{10}$ UWA Oceans Institute, University of Western Australia, 35 Stirling Highway, Crawley 6009,

Australia

${ }^{11}$ National Marine Science Centre, School of Environment, Science and Engineering, Southern Cross University, PO Box 4321, Coffs Harbour, 2450 NSW, Australia

${ }^{12}$ CSIRO Oceans and Atmosphere, Ecosciences Precinct, 41 Boggo Road, Dutton Park 4102, Australia

${ }^{13}$ School of Biological Sciences University of Queensland, St. Lucia, QLD, Australia

${ }^{14}$ Centre d’Estudis Avançats de Blanes - CSIC, Blanes, Spain. 


\begin{abstract}
Mangrove soils represent a large sink for otherwise rapidly recycled carbon (C). However, widespread deforestation threatens the preservation of this important $\mathrm{C}$ stock. It is therefore imperative that we understand global patterns in mangrove soil $\mathrm{C}$ stocks and their susceptibility to remineralization. Here, we present patterns in mangrove soil $\mathrm{C}$ stocks across hemispheres, latitudes, countries, and mangrove community compositions, and estimated potential annual $\mathrm{CO}_{2}$ emissions for countries where mangroves occur. Global potential $\mathrm{CO}_{2}$ emissions from soils as a result of mangrove loss was estimated to be $\sim 7.0{\mathrm{Tg} \mathrm{yr}^{-1}}^{-1}$. Countries with the highest potential $\mathrm{CO}_{2}$ emissions from soils are Indonesia (3410 Gg $\mathrm{CO}_{2} \mathrm{yr}^{-1}$ ) and Malaysia (1288 $\mathrm{Gg} \mathrm{CO}_{2} \mathrm{yr}^{-1}$ ). The patterns described serve as a baseline by which countries can assess their mangrove soil $\mathrm{C}$ stocks and potential emissions from mangrove deforestation.
\end{abstract}

\title{
Introduction
}

Mangroves cover just $0.1 \%$ of the Earth’s continental surface $\left(\sim 81,484.96 \mathrm{~km}^{2}\right)^{1}$, but have been identified as some of the most carbon (C) rich forests on earth ${ }^{2-4}$. Mangroves differ from terrestrial forests in their ability to store large amounts of $C$ in their soils over millenary time scales. Complex root structures, high sedimentation rates, waterlogged soils free from risk of fires, and anoxic soils in mangroves results in $C$ burial rates that are an order of magnitude greater and soil $\mathrm{C}$ turnover rates a thousand times slower than those in terrestrial forests ${ }^{5,6}$. The ability of mangrove ecosystems to store large amounts of soil C (5-10.4 Pg globally) ${ }^{7,8}$ for millennia makes these ecosystems important $C$ sinks, and reducing or preventing greenhouse gas emissions from the loss of these soil $\mathrm{C}$ stocks is a low-cost option for mitigating climate change $^{9,10}$. However, we currently lack robust global estimates for soil C stocks in mangroves, which are required to assess the potential for habitat loss to contribute to annual $\mathrm{CO}_{2}$ emissions and identify important blue $\mathrm{C}$ hotspots requiring conservation.

Mangroves and their associated soil C face a multitude of anthropogenic threats (e.g., coastal development, drainage, pollution), leading to large-scale global declines ${ }^{11,12}$. Overall, more than one third of the world's mangroves have vanished over the past 60 years ${ }^{1,11}$. Despite conservation measures being deployed in many nations (e.g. Australia), mangroves continue to be lost at a global rate of about $0.2 \%$ per year ${ }^{1}$. Only Bangladesh and Guinea-Bissau, out of the top 15 countries for mangrove area, have experienced no net loss from 2000-2012,13. This global decline in mangroves raises concerns about the fate of the large $C$ deposits stored within their soils. Several studies have suggested that degradation and removal of vegetated coastal habitats have the potential to disturb soil $\mathrm{C}$ down to depths of $1 \mathrm{~m}$, leading to its remineralization to $\mathrm{CO}_{2}$ ${ }^{14,15}$. Because mangrove soil $\mathrm{C}$ deposits take thousands of years to form, once disrupted they cannot be regained over meaningful human time-scales by just restoring the forest. As a result, the remineralization of mangrove soil $\mathrm{C}$ may add significantly to the component of anthropogenic greenhouse gas (GHG) emissions designated as "land use change" still unaccounted for in global C inventories ${ }^{16}$.

Estimates of potential GHG emissions associated with mangrove loss thus far have been derived from global averages in soil $\mathrm{C}$ stocks and the global area lost annually ${ }^{15}$. However, these estimates assume losses are randomly distributed relative to soil C stocks, which may not be the case. Moreover, such first order global estimates provide no guidance as to where mangrove conservation will be most effective in avoiding GHG emissions. Here we provide improved estimates of global soil $\mathrm{C}$ stocks underlying mangroves, the susceptibility of these stocks to 
remineralization, and areas where soil $\mathrm{C}$ data are deficient or missing. We resolve the regional variability in mangrove soil $C$ stocks through a combination of estimates from published and unpublished sources as well as regional estimates of annual rates of habitat decline ${ }^{1}$. This country-specific approach allows us to define where mangrove losses may have the highest contribution to annual $\mathrm{CO}_{2}$ emissions. Overall our data set includes $\mathrm{C}$ stocks for 1230 distinct sampling locations (supplementary data) from 48 countries (out of 105 countries supporting mangrove habitats) encompassing $88 \%$ of the global mangrove area, thereby doubling the number of countries in past global estimates ${ }^{8}$.

\section{Results}

\section{Global and National Trends}

Data quality among countries was highly variable (Table S1 \& S2). Of the 48 countries with mangrove soil C data, 19 countries scored less than $70 \%$ in their total data quality score. Furthermore, 55\% relied heavily on the use of a pedotransfer function for estimating bulk density data and 50\% of countries were missing good estimates of soil C content deeper than $50 \mathrm{~cm}$. In terms of how well the data represented mangrove genera occurring in each country, 15 of 48 countries had less than 30\% coverage of their mangrove genera. Most of the countries were in areas where mangrove species diversity is very high (e.g., Asia and Pacific Islands). Coverage of marine eco-regions within countries was overall quite high, and only three countries (Federated States of Micronesia, Papua New Guinea, and Saudi Arabia) had less than $30 \%$ of their marine eco-regions with mangroves represented in the data.

Mangroves in the northern and southern hemispheres were not significantly different in terms of soil OC storage per unit area $(t=1.584$, df $1227, \mathrm{P}=0.1132)$. However, we did find a significant difference in soil $\mathrm{C}$ storage per unit area across latitudinal bands $\left(\mathrm{F}_{6,1222}=22.5, \mathrm{P}<\right.$ 0.001 ; Fig. 1), with mangroves between $0-10^{\circ} \mathrm{N}$ having the highest soil $\mathrm{C}$ storage per unit area $\left(345.9 \pm 232.5 \mathrm{Mg} \mathrm{C} \mathrm{ha}^{-1}\right)$ and mangroves between $20-30^{\circ} \mathrm{S}$ having the lowest (222.2 \pm 151.4 $\left.\mathrm{Mg} \mathrm{C} \mathrm{ha}{ }^{-1}\right)$.

Overall, mixed assemblages of mangroves had 20\% higher soil C stocks compared to monotypic stands (df 1122, $\mathrm{t}=5.3149, \mathrm{P}<0.001$; Fig. 2A.). Genera richness was significantly associated with soil $\mathrm{C}$ stocks $\left(\mathrm{F}_{8,979}=2.504, \mathrm{P}=0.011\right.$; Fig. $\left.2 \mathrm{~B}\right)$, with assemblages containing five mangrove genera having the highest $\mathrm{C}$ stocks (1337.96 $\mathrm{Mg} \mathrm{C} \mathrm{ha}^{-1}$ ) and those containing 7 or 8 having the lowest (187.7 $\mathrm{Mg} \mathrm{C} \mathrm{ha}^{-1}$ and $149.5 \mathrm{Mg} \mathrm{C} \mathrm{ha}^{-1}$, respectively). C stocks differed 4fold among genera within monotypic stands $\left(\mathrm{F}_{13,624}=7.07, \mathrm{P}<0.001\right.$; Fig. $\left.2 \mathrm{C}\right)$, with Laguncularia and Rhizophora forests having the highest stocks (424 $262 \mathrm{Mg} \mathrm{C} \mathrm{ha}^{-1}, 388 \pm 227$, Mg C ha ${ }^{-1}$, respectively).

We estimate that mangrove soils store $\sim 2.6 \mathrm{Pg} \mathrm{C}$ (equivalent to $9.5 \mathrm{Pg}$ of $\mathrm{CO}_{2}$ ) globally, with an average soil C stock per unit area of $283 \pm 193 \mathrm{Mg} \mathrm{C} \mathrm{ha}^{-1}$. The four nations with the highest total C stocks in mangrove soils were Indonesia (831 Tg C), Brazil (236 Tg C), Malaysia (199 Tg C), and Mexico (111 Tg C) (Table S3; Fig. 3A), while mangroves with the highest C storage per unit area (Fig. 3B) occurred in the Democratic Republic of Congo (936 Mg C ha-1), Gabon (736 Mg C ha ${ }^{-1}$ ), Belize (647 Mg C ha-1), and Cameroon (597 Mg C ha-1), (Table S3; Fig. 3B).

Global mangrove habitat loss and potential $\mathrm{CO}_{2}$ emissions 
Potential annual C losses from mangroves were estimated to be $2.0 \mathrm{Tg} \mathrm{C}^{-1} \mathrm{yr}^{-1}$, equivalent to 7.3 Tg of $\mathrm{CO}_{2}$ emitted annually from disturbed mangrove soils (Table S4; Fig. 3C). The top five countries with the highest potential for annual soil $\mathrm{C}$ stock losses, and thus $\mathrm{CO}_{2}$ emissions, due to mangrove habitat decline are Indonesia (0.93 $\mathrm{Tg} \mathrm{C} \mathrm{yr}^{-1}$ ), Malaysia (0.35 $\left.\mathrm{Tg} \mathrm{C} \mathrm{yr}^{-1}\right)$, United States (0.06 Tg C yr ${ }^{-1}$ ), Brazil (0.05 Tg C yr ${ }^{-1}$ ), and Thailand (0.04 Tg C yr ${ }^{-1}$ ). Although we lacked soil $\mathrm{C}$ data for Myanmar, we used the global average soil $\mathrm{C}$ stock per unit area to estimate that it could be losing $0.21 \mathrm{Tg} \mathrm{C} \mathrm{yr}^{-1}$, putting Myanmar third for highest potential annual soil C stock losses. Combined, these six countries account for $\sim 90 \%$ of the total potential annual soil C stock losses (Fig. 4).

We found a significant relationship between country-specific total C stocks and country-specific mangrove area $\left(\mathrm{f}_{1,48}=1755, \mathrm{P}<0.001, \mathrm{r}_{\text {adj }}^{2}=0.972\right.$; Fig. 5). The model slope was not significantly different from $1: 1\left(\mathrm{f}_{1,46}=2.7889, \mathrm{P}=0.102\right)$. In addition, we found a significant relationship between country-specific $\mathrm{C}$ stocks per unit area and country-specific potential annual $\mathrm{CO}_{2}$ emissions due to deforestation; although the variation explained by this relationship was only $9 \%\left(f_{1,40}=7.122, P=0.029, r^{2}\right.$ adj $=0.09$; Fig. 6$)$. The model slope was not significantly different from $1: 1\left(\mathrm{f}_{1,40}=0.971, \mathrm{P}=0.334\right)$.

\section{Discussion}

Mangrove forests with the highest soil C stocks per unit area were associated with tropical areas between $0-10^{\circ}$ of latitude, but had no clear latitudinal trend. This pattern in soil C stocks across latitudes differs from mangrove above-ground biomass, which progressively increases towards the tropics ${ }^{3,17,13}$. This suggests that $C$ hotspots for mangrove soils may not overlap with those for above-ground biomass.

Wetlands and vegetated coastal ecosystems like mangroves provide a wealth of ecosystem services, but often contain low plant diversity with many stands being monotypic ${ }^{18}$. Yet, we found that mixed stands had $20 \%$ higher soil C stocks per unit area than monotypic stands. In monotypic stands, forest with Laguncularia and Rhizophora were associated with the highest soil C stocks. Rather than a linear increase in soil C stocks per unit area with increasing genera richness we found that mangrove stands containing 5 genera had 70-90\% higher soil C stocks per unit area than all other richness levels. This analyses only shows the association between soil $\mathrm{C}$ stocks and mangrove genus or genera richness; it does not necessarily imply a causal link between mangrove community composition and enhanced soil C stocks. However, these global trends suggest that research investigating the effects of mangrove community composition and species richness on $\mathrm{C}$ accumulation and preservation in soils may be warranted. Especially when one considers that many mangrove afforestation programs only plant one or two species, generally of the genus Rhizophora or Avicennia ${ }^{19,20}$.

We estimate that mangrove soils store $\sim 2.6 \mathrm{Pg} \mathrm{C}$ (equivalent to $\sim 9.5 \mathrm{Pg}$ of $\mathrm{CO}_{2}$ ) globally. However, several studies have documented that mangrove soils exceed $1 \mathrm{~m}^{2,21}$; thus, constraining our estimates to a $1 \mathrm{~m}$ depth likely underestimates the global soil $\mathrm{C}$ stock in mangroves. When combined with above-ground $\mathrm{C}$ biomass ${ }^{17}$, mangroves store $\sim 4.4 \mathrm{Pg}$ C. Our global soil C estimate is $\sim 54-78 \%$ lower than those previously reported ${ }^{7,8}$, despite our average soil C stock per unit area of $283 \pm 193 \mathrm{Mg} \mathrm{C} \mathrm{ha}^{-1}( \pm \mathrm{SD})$ being similar to past estimates ${ }^{7}$. Our lower estimate was largely due to our use of a more recent and conservative estimate of global mangrove area by Hamilton and Casey ${ }^{1}$, which was $~ 39 \%$ lower than that reported by Giri et al. (2011). The large discrepancies in estimates of mangrove habitat area and its effect on mangrove soil C stocks 
underscores the need to develop more robust and standardized methods for measuring mangrove habitat area ${ }^{22}$.

We found substantial variation across countries in total soil C stocks, ranging from 831 Tg C in Indonesia to 0.0001 Tg C in Egypt. Nearly all (97\%) of the variation in total soil C stocks across countries could be explained by differences in mangrove habitat area (Fig. 5). In fact, none of the top five countries for total soil $\mathrm{C}$ stocks were in the top five for $\mathrm{C}$ densities; again this highlights the need for better standardized methods for estimating mangrove area. Nevertheless, we also found large variation in soil C stocks per unit area across countries, which ranged over an order of magnitude from $936 \mathrm{Mg} \mathrm{C} \mathrm{ha}^{-1}$ in the Democratic Republic of Congo to $72 \mathrm{Mg} \mathrm{C} \mathrm{ha}^{-1}$ in the Saudi Arabia. Although the scope of data collection in this study precludes further investigations into the source of this variation, several individual studies suggest that sitespecific physiochemical properties (e.g. karstic soils, distance from seaward edge, salinity, nitrogen and phosphorus content of the soil) play a major role in soil $\mathrm{C}$ storage in mangroves and may be leading to the observed patterns in this study ${ }^{2,23}$.

Our study also highlights major gaps in mangrove soil $\mathrm{C}$ data. We were able to obtain mangrove soil $\mathrm{C}$ data for 48 countries, encompassing $88 \%$ of the global mangrove extent. However, we still lack soil $\mathrm{C}$ data for 44 countries where mangroves occur. Although many of these are countries with limited mangrove cover, we currently have no estimates of soil C stocks for mangroves in Myanmar or Cuba, which rank $8^{\text {th }}$ and $14^{\text {th }}$ in mangrove cover and $1^{\text {st }}$ and $18^{\text {th }}$, respectively for annual declines in mangrove habitat ${ }^{1}$. Furthermore, African countries are underrepresented, with no data for 17 countries and only sparse data for many others. This assessment should, therefore, lead to efforts to address these gaps.

Mangroves support a wealth of ecosystem services, and their decline therefore results in lost social-economical benefits. Globally, 131-639 km² (Mangrove Forests of the Word and Terrestrial Ecosystems of the World-Mangrove Biome estimates, respectively) of mangroves are destroyed annually ${ }^{1}$. When combined with per area soil $\mathrm{C}$ stocks this equates to a potential loss

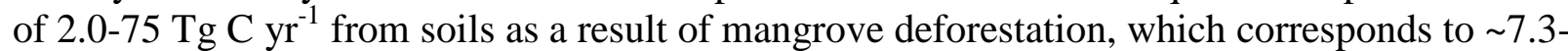
$275 \mathrm{Tg}$ of $\mathrm{CO}_{2}$ emissions. The potential gross annual $\mathrm{CO}_{2}$ emissions from the remineralization of soil $\mathrm{C}$ in mangroves, thus is equivalent to $0.2-6 \%$ of those from terrestrial deforestation globally $^{24}$. We estimated the potential gross annual emissions with the assumption that $43 \%$ of the soil C stocks down to $1 \mathrm{~m}$ are eventually remineralized following mangrove loss ${ }^{14,15,25}$. However, one of the greatest uncertainties in blue $\mathrm{C}$ research is the fate (e.g., remineralized, transported, etc.) of soil C following habitat disturbance. Although our approach follows IPCC protocols and common practice in the literature, which standardizes loss to $1 \mathrm{~m}$ in the soil, disturbances can influence $C$ stocks at greater depths ${ }^{26,27}$. Since many mangrove ecosystems around the world have soil depths that extend well beyond $1 \mathrm{~m}^{21,28}$, standardizing losses to this depth may underestimate $\mathrm{CO}_{2}$ emissions from soils. Refining potential soil $\mathrm{CO}_{2}$ emission estimates will require further studies on the fate of soil $\mathrm{C}$ stocks after mangrove ecosystems are disturbed or destroyed, a topic urgently in need of research.

The top four countries with the highest potential gross annual $\mathrm{CO}_{2}$ emissions due to mangrove deforestation are Indonesia (3410 Gg CO $2 \mathrm{yr}^{-1}$ ), Malaysia (1288 $\mathrm{Gg} \mathrm{CO}_{2} \mathrm{yr}^{-1}$ ), United States (205 Gg CO $\mathrm{yr}^{-1}$ ), and Brazil (186 Gg CO $2 \mathrm{yr}^{-1}$ ). Together these countries account for $\sim 86 \%$ of the total potential emissions due to mangrove deforestation, with Indonesia alone accounting for $\sim 50 \%$. Brazil and Indonesia have been at the center of many debates about 
deforestation, and combined they account for $55 \%$ of total emissions from tropical terrestrial deforestation ${ }^{29}$. Soil C stocks per unit area only explain $\sim 9 \%$ of the variability in potential gross annual $\mathrm{CO}_{2}$ emissions (Fig. 6). These results suggest that relatively low levels of deforestation in countries with high soil $\mathrm{C}$ stocks per unit area is currently constraining potential $\mathrm{CO}_{2}$ emissions. Among these important countries, The Democratic Republic of Congo, Gabon, Cameroon, Belize, and Colombia have the highest $\mathrm{C}$ stocks per unit area and currently have relatively low or moderate levels of deforestation. However, all five of these countries have declining Ocean Health Indices ${ }^{30}$, and stable (Belize and The Democratic Republic of Congo) or increasing levels of mangrove decline (Colombia, Cameroon, Gabon) ${ }^{1}$. Our results suggest that mangrove conservation efforts should be most effective if targeting the highest potential emitters, along with mangroves with C-rich soils (>500 $\mathrm{Mg} \mathrm{C} \mathrm{ha}^{-1}$ ).

Nations with no available data on soil C stocks may rank among such hot spots representing priority areas for mangrove conservations, providing an additional motivation to address this gap. For example, we currently lack soil $\mathrm{C}$ data for Myanmar, which has the highest annual rates $(\sim 1 \%)$ of mangrove deforestation in the world ${ }^{1}$. If we use the average global soil $\mathrm{C}$ stock per unit area to estimate potential annual $\mathrm{C}$ stock losses, Myanmar would have the third highest potential annual $\mathrm{CO}_{2}$ emissions (784 $\mathrm{Gg} \mathrm{CO}_{2} \mathrm{yr}^{-1}$ ) and would contribute to $18 \%$ of the total potential $\mathrm{CO}_{2}$ emission due to mangrove deforestation.

In general, aquaculture is the major cause of mangrove removal in Asia and South America ${ }^{20,31,32}$, and globally it is responsible for $52 \%$ of mangrove declines ${ }^{33}$. This is concerning for two primary reasons: 1) Conversion of mangroves to aquaculture ponds significantly increases $\mathrm{CO}_{2}$ emissions from the soil ${ }^{25,27}$, because the excavation and oxidation of soils during pond construction can exceed several meters. Furthermore, the construction of aquaculture ponds can lead to further mangrove losses in surrounding areas as the ponds leach high levels of nutrients and alter tidal flow. 2) The demand for seafood will double to $14.8 \mathrm{~m}$ tons by 2030, with at least $50 \%$ supplied by aquaculture ${ }^{34}$. In response to these projections many countries in Asia and South America are ramping up their aquaculture production, and the Indonesian Ministry of Marine Affairs and Fisheries has set a target to increase aquaculture production over the next 10 years by $61 \%{ }^{31,35}$. In addition to aquaculture, the conversion of mangroves to rice agriculture and oil palm plantations is an emerging problem in many Southeast Asian countries (e.g, Myanmar, Malaysia, and Indonesia) ${ }^{36}$.

Mangroves store an exceptional amount of $\mathrm{C}$ in their soils. However, a global estimate alone does not help to target conservation efforts, because soil $\mathrm{C}$ stocks are highly variable across hemispheres, latitudes, countries, and plant community compositions. Here, we provide estimates for how $\mathrm{C}$ stocks and potential $\mathrm{CO}_{2}$ emissions vary across these variables. In general, our analyses show that protecting large areas of mangrove forests may be more beneficial for preventing greenhouse gas emissions from mangrove soils as a result of forest loss than selecting for small areas with high soil $\mathrm{C}$ content. Furthermore, global conservation efforts aimed at protecting blue carbon stocks should focus on; 1) reducing intense deforestation in countries with large mangrove area and high soil $\mathrm{C}$ stock per unit area. In fact, eliminating mangrove deforestation entirely in just Malaysia and Indonesia, would reduce global soil $\mathrm{CO}_{2}$ emissions from mangrove deforestation by as much as $~ 70 \%$. 2) Maintain low deforestation rates in countries with relatively large areas of mangroves and high soil C stocks per unit area, with a particular focus on The Democratic Republic of Congo, Gabon, and Cameroon. As global demand for food and biofuels intensifies, so will social, ecological, and economical debates 
about the future of mangroves. As a result, large-scale estimates on the value of mangroves as $\mathrm{C}$ sinks, as well as other ecosystem services, are essential for managers and policy makers to accurately evaluate economic and ecological trade-offs for the management of mangrove forests. The patterns presented in this study provides a baseline assessment of mangrove soil C stocks and potential emissions from mangrove deforestation and degradation, while identifying hotspots for priority conservation and gaps that need to be urgently addressed.

\section{References}

1. Hamilton, S. \& Casey, D. Creation of high spatiotemporal resolution global database of continuous mangrove forest cover for the 21st century: A big-data fusion approach. Glob. Ecol. Biogeogr. 25, 729-738 (2016).

2. Donato, D. C. et al. Mangroves among the most carbon-rich forests in the tropics. Nat. Geosci. 4, 293-297 (2011).

3. Twilley, R. R., Chen, R. \& Hargis, T. Carbon sinks in mangroves and their implications to carbon budget of tropical coastal ecosystems. Water, Air Soil Pollut. 64, 265-288 (1992).

4. Bouillon, S. et al. Mangrove production and carbon sinks: A revision of global budget estimates. Global Biogeochem. Cycles 22, n/a-n/a (2008).

5. Mcleod, E. et al. A blueprint for blue carbon: toward an improved understanding of the role of vegetated coastal habitats in sequestering CO2. Front. Ecol. Environ. 9, 552-560 (2011).

6. Alongi, D. M. Carbon sequestration in mangrove forests. Carbon Manag. 3, 313-322 (2012).

7. Duarte, C. M., Losada, I. J., Hendriks, I. E., Mazarrasa, I. \& Marbà, N. The role of coastal plant communities for climate change mitigation and adaptation. Nat. Clim. Chang. 3, 961-968 (2013).

8. Jardine, S. L. \& Siikamäki, J. V. A global predictive model of carbon in mangrove soils. Environ. Res. Lett. 9, 104013 (2014).

9. Siikamäki, J., Sanchirico, J. N. \& Jardine, S. L. Global economic potential for reducing carbon dioxide emissions from mangrove loss. Proc. Natl. Acad. Sci. 109, (2012).

10. Murdiyarso, D. et al. The potential of Indonesian mangrove forests for global climate change mitigation. Nat. Clim. Chang. 5, 8-11 (2015).

11. Alongi, D. M. Present state and future of the world's mangrove forests. Environ. Conserv. 29, 331-349 (2002).

12. Lovelock, C. E. et al. The vulnerability of Indo-Pacific mangrove forests to sea-level rise. Nature 526, 559-563 (2015).

13. Giri, C. et al. Status and distribution of mangrove forests of the world using earth observation satellite data. Glob. Ecol. Biogeogr. 20, 154-159 (2011). 
14. Fourqurean, J. W. et al. Seagrass ecosystems as a globally significant carbon stock. Nat. Geosci. 5, 505-509 (2012).

15. Pendleton, L. et al. Estimating global 'blue carbon' emissions from conversion and degradation of vegetated coastal ecosystems. PLoS One 7, e43542 (2012).

16. $\quad$ IPCC. Climate Change 2007: The Physical Sciences Basis. In: Contribution of Working Group I to the Fourth Assessment Report of the Intergovernmental Panel on Climate Change. (2007).

17. Hutchison, J., Manica, A., Swetnam, R., Balmford, A. \& Spalding, M. Predicting global patterns in mangrove forest biomass. Conserv. Lett. 7, 233-240 (2014).

18. Field, C. B. et al. Mangrove biodiversity and ecosystem function. Glob. Ecol. Biogeoraphy Lett. 7, 3-14 (1998).

19. Datta, D., Chattopadhyay, R. N. \& Guha, P. Community based mangrove management: A review on status and sustainability. J. Environ. Manage. 107, 84-95 (2012).

20. Ferreira, A. C. \& Lacerda, L. D. Degradation and conservation of Brazilian mangroves, status and perspectives. Ocean Coast. Manag. 125, 38-46 (2016).

21. Sanders, C. J. et al. Are global mangrove carbon stocks driven by rainfall? J. Geophys. Res. Biogeosciences (2016). doi:10.1002/2016JG003510

22. Friess, D. A. \& Webb, E. L. Variability in mangrove change estimates and implications for the assessment of ecosystem service provision. Glob. Ecol. Biogeogr. 715-725 (2014). doi:10.1111/geb.12140

23. Adame, M. F. et al. Carbon stocks of tropical coastal wetlands within the karstic landscape of the Mexican Caribbean. PLoS One 8, e56569 (2013).

24. van der Werf, G. R. et al. CO2 emissions from forest loss. Nat. Geosci. 2, 737-738 (2009).

25. Lovelock, C. E., Ruess, R. W. \& Feller, I. C. CO2 efflux from cleared mangrove peat. PLoS One 6, 1-4 (2011).

26. Kauffman, J. B., Hernandez Trejo, H., del Carmen Jesus Garcia, M., Heider, C. \& Contreras, W. M. Carbon stocks of mangroves and losses arising from their conversion to cattle pastures in the Pantanos de Centla, Mexico. Wetl. Ecol. Manag. 24, 203-216 (2016).

27. Kauffman, J. B., Heider, C., Norfolk, J. \& Payton, F. Carbon stocks of intact mangroves and carbon emissions arising from their conversion in the Dominican Republic. Ecol. Appl. 24, 518-527 (2014).

28. Donato, D. C. et al. Mangroves among the most carbon-rich forests in the tropics. Nat. Geosci. 4, 293-297 (2011).

29. Harris, N. L. et al. Baseline Map of Carbon Emissions from Deforestation in Tropical Regions. Science (80-. ). 336, 1573-1576 (2012).

30. Halpern, B. S. et al. Patterns and emerging trends in global ocean health. PLoS One 10, 
(2015).

31. Ilman, M., Dargusch, P., Dart, P. \& Onrizal. A historical analysis of the drivers of loss and degradation of Indonesia's mangroves. Land use policy 54, 448-459 (2016).

32. Ahmed, N. \& Glaser, M. Coastal aquaculture, mangrove deforestation and blue carbon emissions: Is REDD+ a solution? Mar. Policy 66, 58-66 (2016).

33. Valiela, I., Bowen, J. L. \& York, J. K. Mangrove forests: One of the world's threatened major tropical environments. Bioscience 51, 807-815 (2001).

34. Msangi, S. et al. Fish to 2030: Prospects for fisheries and aquaculture. (2013).

35. Armitage, D. Socio-institutional dynamics and the political ecology of mangrove forest conservation in Central Sulawesi, Indonesia. Glob. Environ. Chang. 12, 203-217 (2002).

36. Richards, D. R. \& Friess, D. A. Rates and drivers of mangrove deforestation in Southeast Asia, 2000-2012. Proc. Natl. Acad. Sci. 201510272 (2015). doi:10.1073/pnas.1510272113 


\section{Acknowledgments}

Support was provided by the CSIRO Coastal Carbon Biogeochemistry Cluster. We also acknowledge the support of The Oceans Institute of the University of Western Australia, the Global Change Institute of The University of Queensland, and the Australian Research Council (Awards DE130101084, LP160100242, LE140100083, and DP150103286) and King Abdullah University of Science and Technology (KAUST) through the baseline fund to CMD. We would like to thank Pat Terletzky-Gese for assistance with GIS.

\section{Author contributions}

TBA, RC, and CEL designed the study. TBA, CEL, HA, PC, CMD, CE, XI, JK, PSL, PIM, OS, CS, IS, and AS contributed data. TBA analyzed the data and drafted the first version of the manuscript. All authors contributed to the writing and editing of the manuscript.

\section{Competing finance interest}

The authors declare no competing financial interests.

\section{Materials and Correspondence}

Data sets and corresponding DOI's will be supplied upon acceptance of the manuscript. Correspondence and requests for materials should be addressed to T.B.A. 


\section{Methods}

We used Google Scholar, Web of Science, personal datasets, and published reports to generate the most robust dataset to date on mangrove soil C stocks. Studies included in the dataset contained both undisturbed and degraded mangrove ecosystems, however, planted mangroves were excluded. At a minimum, studies needed to include latitude and longitude of the sample location, percent organic carbon (hereon referred to as $\mathrm{C}$ ) content of the soil or loss on ignition (LOI), core depth, and section thickness. In some cases, the original data was presented as an average across multiple sites; in these cases, GPS coordinates of the coastal middle point were used. Studies reporting LOI were converted to percent $C$ by dividing by 2.07 , an estimate of the ratio of organic matter to $\mathrm{C}$ concentration ${ }^{37}$. Studies that included measures of organic matter concentrations in the soil were converted by multiplying the organic matter content by 0.58 . The inclusion of studies reporting LOI or percent organic matter allowed us to include data from less developed nations. We standardized soil C stocks down to 1 meter in the soil. Studies containing shorter depth profiles than $1 \mathrm{~m}$ were extrapolated by taking the average percent $\mathrm{C}$ content and dry bulk density from known depths and multiplying it to 1 meter. We used the pedotransfer function in equation 1 to estimate dry bulk density in studies that did not report one.

dry bulk density $=1.25 * \% \mathrm{C}^{-0.5163}$

We quantified data quality for each country by scoring characteristics relating to the quality of individual data points and the overall country-wide data set. A total of seven categories were included and quality scores were ranked on a scale of 0 -3, with an overall score of 21 being the highest possible. Individual data point categories were related to the quality of the data needed to estimate $\mathrm{C}$ stocks down to $1 \mathrm{~m}$ in the soil, as well as the publication quality. Individual data point categories include; quality of $\mathrm{C}$ stock data, quality of down-core stock data to $1 \mathrm{~m}$, quality of percent organic carbon data, quality of bulk density data, and quality of the publication. Individual data point scores for each country were averaged within a category. Overall countrywide data set characteristics were related to the extent of data coverage for that county and included; extent of mangrove genera covered and extent of marine ecoregions covered (MEOW). We used MEOW to qualify data extent because ecoregions represent areas of relatively homogeneous species compositions that have distinct communities and biogeographical forcing agents (e.g., nutrient inputs, freshwater influx, temperature, sediments, currents, and coastal complexity) compared to adjacent systems. To determine the extent of MEOW regions covered we overlayed MEOW, site locations, and mangrove habitat extent GIS layers. The scoring matrix is presented in Supplementary Table 1.

We investigated how soil C stocks per unit area differed across hemispheres and latitudes. In some cases, studies did not report latitude coordinates, but rather supplied a map of sample locations. In these instances, we used Google Earth to manually obtain a more precise location. To examine the difference between northern and southern hemispheres in $\mathrm{C}$ stocks per unit area we used a paired-t test. To examine differences among latitudes in soil C stocks per unit area we used a One-way ANOVA with latitude grouped into $10^{\circ}$ latitudinal belts $(0-10,10-20,20-30,30-$ 40) either side of the equator. All analyses were conducted using the statistical programming package R (R Development Core Team 2015).

We also assessed how different aspects of the mangrove community composition affected C stocks per unit area. Studies were included in this analysis if they contained information about the genus or species present in the study location. Stands were considered monotypic if they 
were dominated ( $>75 \%$ ) by a single genus of mangrove. The most commonly used classification for dominance was based on number of individuals, however, biomass was also commonly used. In cases where quantitative measurements of genera composition were not used we accepted qualitative statements of dominance by the author of the study. We assessed the effects of mixed versus monotypic stands on $C$ storage per unit area using a paired t-test. We looked at the effects of mangrove genera richness and mangrove genus in monotypic stands on $\mathrm{C}$ storage per unit area using linear mixed effect models with the statistical programming package R. We included study ID as a random factor in models looking at genera richness and genus to account for the fact that in some cases data came predominantly from only one or two studies.

To scale up to country, soil C stocks per unit area were averaged across all sites within a country and then multiplied by the Mangrove Forests of the Word (MFW) country-specific mangrove habitat area for $2014^{1}$. For the 57 countries that lacked soil C data we used the average global C stocks per unit area of $283 \pm 194 \mathrm{Mg} \mathrm{C} \mathrm{ha}^{-1}$. We used MFW as it is more conservative than the Terrestrial Ecosystems of the World-Mangrove Biome (TEOW) ${ }^{1}$. To standardize our countries with Hamilton and Casey ${ }^{1}$ mangrove habitat estimate we combined French Guiana and Guadeloupe by taking the average of their soil C stocks. The global mangrove soil C stock was estimated by summing all country-specific soil C stocks together.

To estimate potential $\mathrm{CO}_{2}$ emissions as a result of mangrove decline, we compiled published data on the effects of different types of disturbances on soil OC stocks or OC content. In total we found 19 studies (Supplementary data). In all cases, studies compared impacted sites from nonimpacted sites, as opposed to pre- and post-disturbance. Disturbances ranged from those that directly affected the soils (aquaculture, agriculture, and urban development) to those that directly affected above-ground biomass with potential impacts to the soils (timber harvest, grazing, pollution, and water diversions), as well as sites that had a combination of both types of disturbances. In addition, $\sim 70 \%$ of the studies quantified impacts down to $80 \mathrm{~cm}$ to $>100 \mathrm{~cm}$ in the soil, while the remianing $30 \%$ quantified effect to 20 or $50 \mathrm{~cm}$ in the soil. Effects on soil OC ranged from $10 \%$ to $85 \%$ (average $43 \% \pm 5 \%$, SE). However, we found that there was no statistical significant difference of the effect of disturbance type (directly effected soils, indirecly effected soils, both) on soil OC (ANOVA: $\mathrm{F}_{3,16}=\mathrm{P}=0.159$ ). As a result, we used the average loss of $43 \%$ for $\mathrm{C}$ stocks down to $1 \mathrm{~m}$ in the soil for all countries. Propogating losses down to 1 $\mathrm{m}$ in the soil is the protocol suggested by the IPCC for estimating $\mathrm{CO}_{2}$ emissions from mangrove ecosystems ${ }^{38}$, and several studies have shown that disturbances can influence soil OC to depths > $1 \mathrm{~m}^{26,27,39}$. Country-level potential annual $\mathrm{CO}_{2}$ emissions from mangrove losses were estimated by first reducing the countries $\mathrm{C}$ storage per unit area by $43 \%$, then we multiplied a countries reduced $\mathrm{C}$ storage per unit area by 3.67 (the molecular weight ratio of $\mathrm{CO}_{2}$ to $\mathrm{C}$ ) and then by its annual mangrove habitat loss ${ }^{1}$. Global annual emissions were estimated by summing all countryspecific potential annual $\mathrm{CO}_{2}$ emissions. Although in some cases it may be unlikely for the entire $43 \%$ of the $\mathrm{C}$ stock to be loss in just one year, thus overestimating annual $\mathrm{CO}_{2}$ emissions, we followed IPCC protocols which state that it should be estimated that all OC in the pool is emitted as $\mathrm{CO}_{2}$ during the year of the land-use conversion ${ }^{38}$.

To help determine which countries should be priorities for conservation we also investigated the relationship between total soil $\mathrm{C}$ stocks by country and country-specific mangrove area, and country-specific soil $\mathrm{C}$ stocks per unit area and potential annual $\mathrm{CO}_{2}$ emissions using linear regressions. For these regressions we only included countries for which soil $\mathrm{C}$ data was available, which excluded the 57 countries where we used the average global soil C stocks per 
unit to estimate total soil $\mathrm{C}$ stocks. For the regression investigating the relationship between country-specific soil $\mathrm{C}$ stocks per unit area and potential annual $\mathrm{CO}_{2}$ emissions we did not include countries with no annual mangrove loss. We tested for statistical differences between the slope of the regressions and a 1:1 relationship using a Wald test in the R package "car". Data were log transformed prior to the analyses to achieve normality of residuals and to improve homoscedasticity of variances.

\section{References}

37. Kauffman, J. B. \& Donato, D. C. Protocols for the measurement, monitoring, and reporting of structure, biomass and carbon stocks in mangrove forests. CIFOR Work. Pap. 86. Cent. Int. For. Res. Bogor, Indones.

38. Kennedy, H., Alongi, D. M. \& Karim, A. CHAPTER 4: Coastal Wetlands. 2013 Supplement to the 2006 IPCC Guidelines for National Greenhouse Gas Inventories: Wetlands (2013). at <http://www.ipcc-nggip.iges.or.jp/public/wetlands/>

39. Bhomia, R. K., Kauffman, J. B. \& McFadden, T. N. Ecosystem carbon stocks of mangrove forests along the Pacific and Caribbean coasts of Honduras. Wetl. Ecol. Manag. 24, 187201 (2016). 


\section{Figure legends}

Figure 1: Latitudinal patterns in mangrove soil carbon (C) stocks per unit area down to $1 \mathrm{~m}$ (mean \pm s.e.).

Figure 2: Effects of community composition on soil carbon (C) stocks per unit area down to $1 \mathrm{~m}$ (mean \pm s.e.). A) The effects of mixed versus monotypic stands on soil C stocks. Monotypic communities are defined as being dominated $(>75 \%)$ by a single mangrove genus. B) Effect of genera richness on soil C stocks. C) Effect of mangrove genus on soil C stocks in monotypic stands.

Figure 3: Soil carbon (C) stocks and potential annual $\mathrm{CO}_{2}$ emissions from mangrove deforestation. A) Total estimated soil C stocks across countries. Striped countries represent those with relatively poor data quality ( $<70 \%$ data quality score). B) Country-specific soil C stocks per unit area down to $1 \mathrm{~m}$. C) Potential gross annual $\mathrm{CO}_{2}$ emissions from soils as a result of annual mangrove habitat declines. Emissions are based on the assumption that $43 \%$ of $\mathrm{C}$ stocks down to $1 \mathrm{~m}$ in the soil are remineralized. Grey areas represent countries where mangroves are known to occur, however, soil $\mathrm{C}$ data was not available. White represents countries where no mangroves occur.

Figure 4: Cumulative potential annual $\mathrm{CO}_{2}$ emissions from soils as a result of mangrove deforestation. Percentages represent $25 \%, 50 \%$, and $75 \%$ of the total potential emissions of 7.0 Tg resulting from mangrove deforestation. Emissions are based on the assumption that $43 \%$ of $\mathrm{C}$ stocks down to $1 \mathrm{~m}$ in the soil are remineralized. Countries represented in the graph contribute $\geq$ $0.1 \%$ to total emissions. Countries not included in the graph, which contribute $<0.01 \%$ to total emissions include: Belize, Vietnam, French Guiana/Guadeloupe, Nicaragua, Guinea, Colombia, Angola, Panama, Nigeria, Ecuador, Tanzania, Solomon Islands, Mozambique, Trinidad and Tobago, Equatorial Guinea, Costa Rica, Madagascar, Fiji, Brunei, El Salvador, Congo, New Caledonia, Ghana, Sri Lanka, New Zealand, Dominican Republic, Jamaica, Ivory Coast, Guyana, China, Kenya, Liberia, Palau, Puerto Rico, Haiti, The Bahamas, Timor-Lest, Japan, South Africa, Federated States of Micronesia, Peru, Grenada, Pakistan, Taiwan, Eritrea, and Benin. Hashed bars represent counties for which no soil $\mathrm{C}$ data existed, as a result potential emissions were calculated using the average global C stocks per unit area of $283 \mathrm{Mg} \mathrm{ha}^{-1}$.

Figure 5: Relationship between country-specific total C stocks and country-specific mangrove area $\left(\mathrm{P}<0.001, \mathrm{r}^{2}\right.$ adj $\left.=0.97\right)$. Solid line represents the model and the dotted line represents the 1:1 slope. The model slope was not significantly different from 1:1 ( $\left.\mathrm{f}_{1,46}=4.026, \mathrm{P}=0.102\right)$. Only countries with soils $\mathrm{C}$ data were included in the model. CO: Colombia; CM: Cameroon; DRC: Democratic Republic of Congo; EC: Ecuador; FG/GP: French Guiana/ Guadeloupe; GA: 
Gabon; HN: Honduras; MG; Madagascar; NG: Nigeria, NZ: New Zealand; PA: Panama; PH: Philippines; TH: Thailand; TZ: Tanzania; USA: United State of America; VE: Venezuela; Viet Nam (VN).

Figure 6: Relationship between country-specific C stocks per unit area and country-specific potential annual $\mathrm{CO}_{2}$ emissions mangrove area. Emissions are based on the assumption that $43 \%$ of $\mathrm{C}$ stocks down to $1 \mathrm{~m}$ in the soil are remineralized. Solid line represents the model and the dotted lines represents the $95 \%$ CI's $\left(P=0.029, \mathrm{r}^{2}\right.$ adj $\left.=0.09\right)$. The model slope was not significantly different from $1: 1\left(f_{1,40}=0.971, P=0.334\right)$. Countries above the upper $95 \% \mathrm{CI}$ represent countries with intense deforestation that results in annual potential $\mathrm{CO}_{2}$ emissions that exceed what would be predicted from their $\mathrm{C}$ stocks per unit area alone. Countries below the lower 95\% CI represent countries with relatively more constrained deforestation, resulting in lower annual potential $\mathrm{CO}_{2}$ emissions than what would be predicted from their $\mathrm{C}$ stocks per unit area alone. DRC: Democratic Republic of Congo; USA: United State of America. 


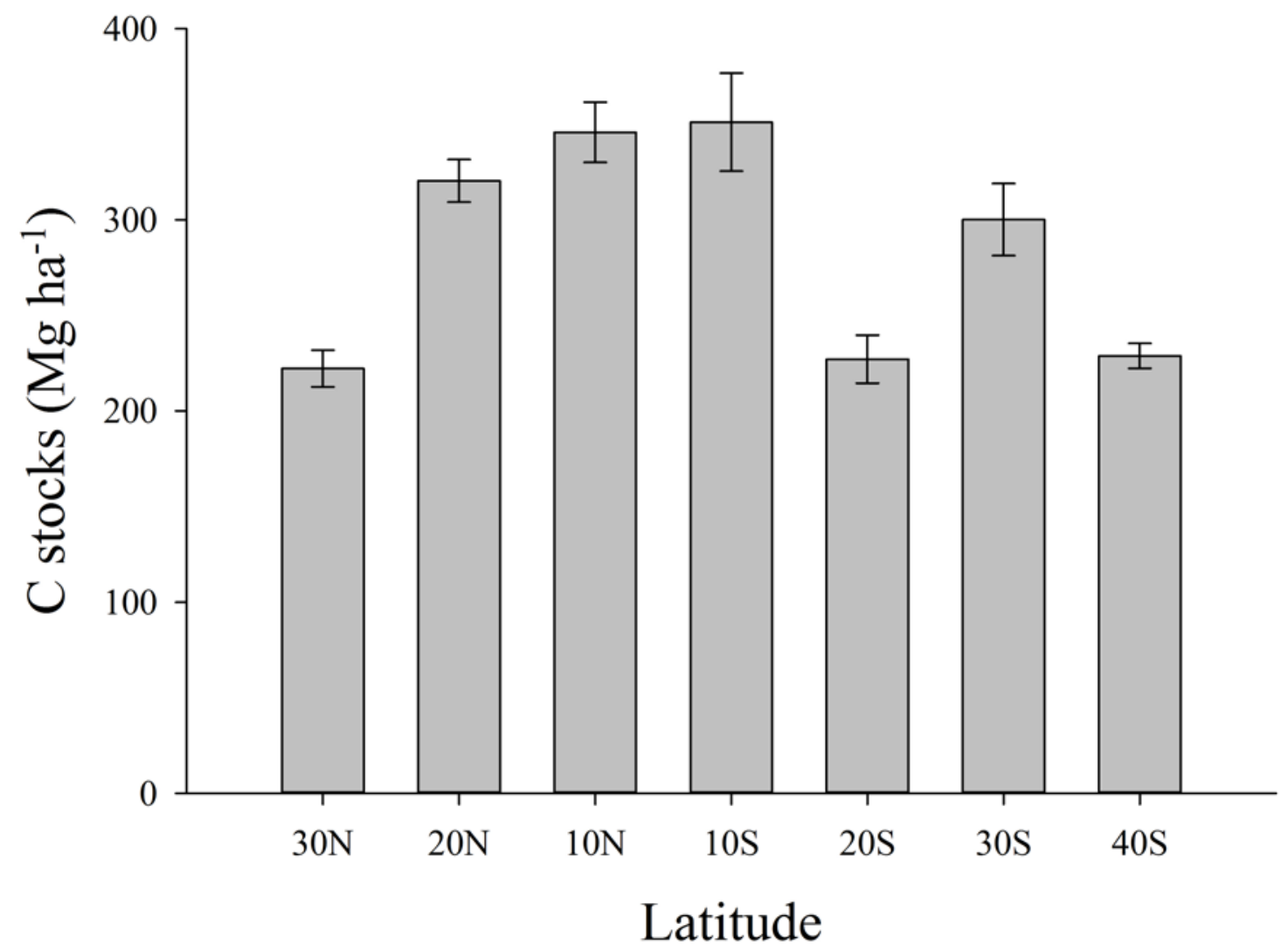

Figure 1 


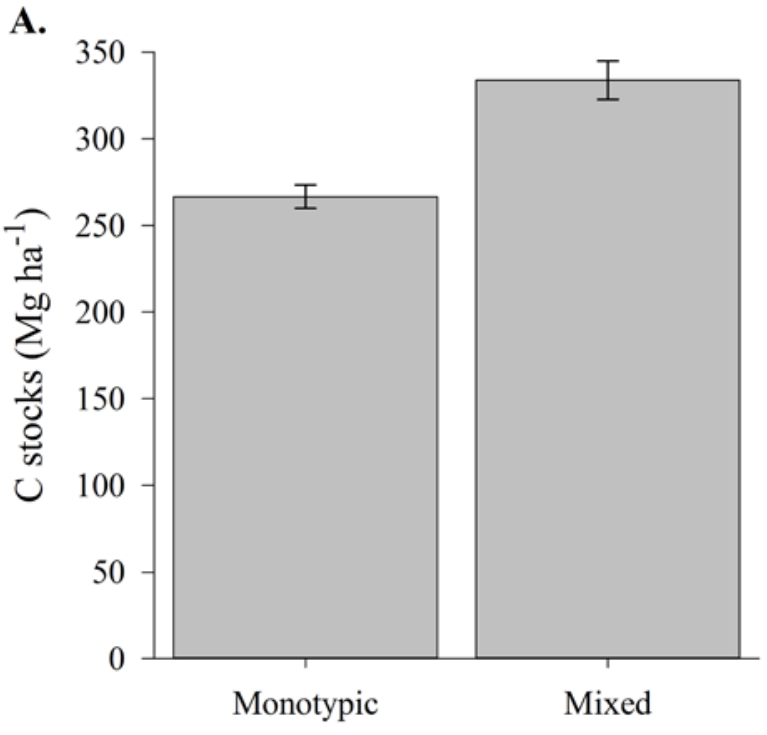

Community composition

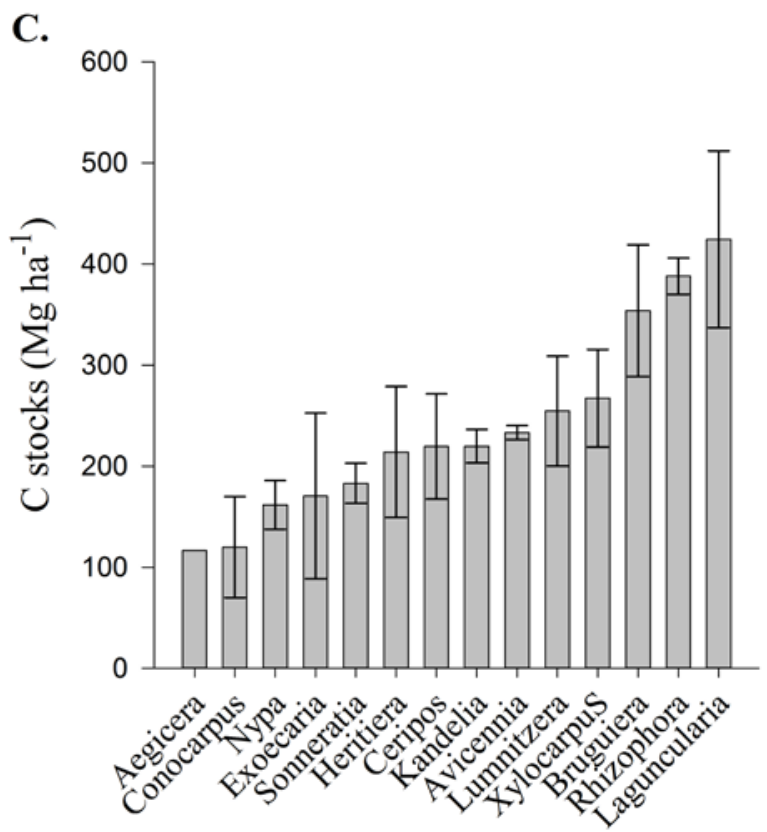

Genus
B.

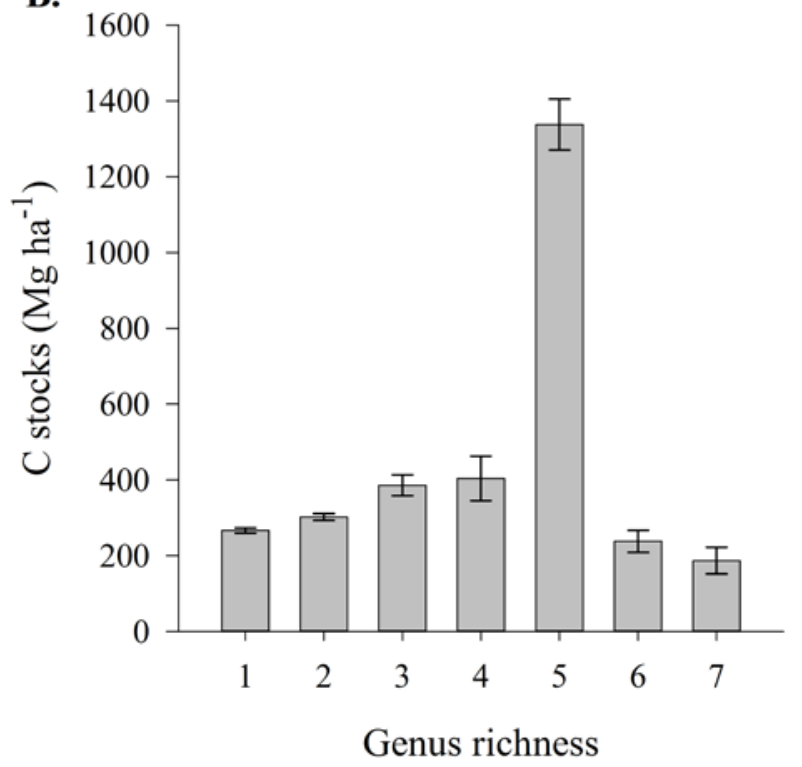




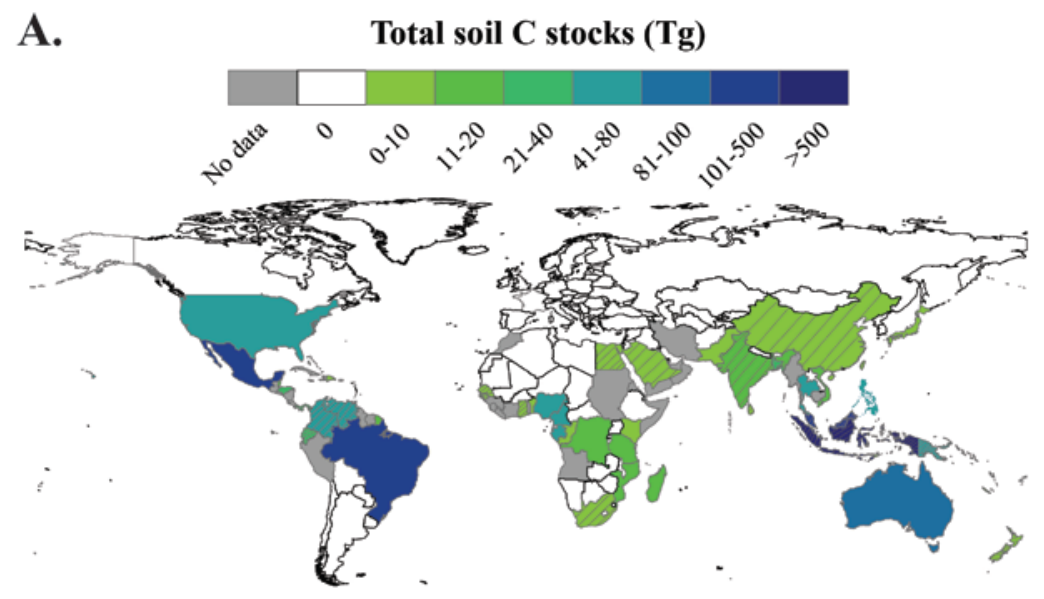

B. C stock per unit area $\left(\mathrm{Mg} \mathrm{ha}^{-1}\right)$

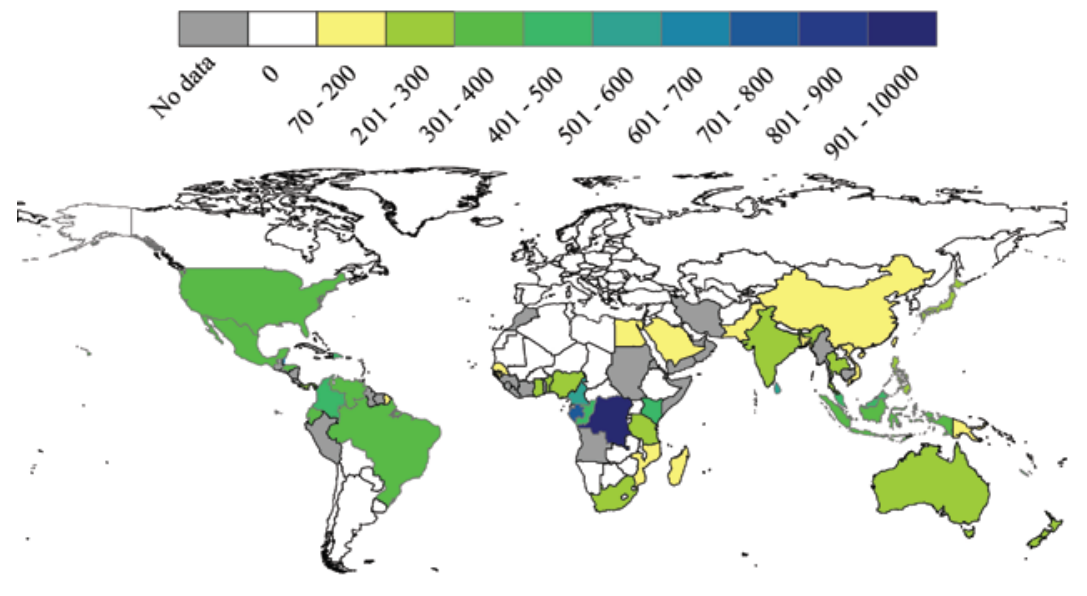

C.

Potential gross annual $\mathrm{CO}_{2}$ emissions (Gg)

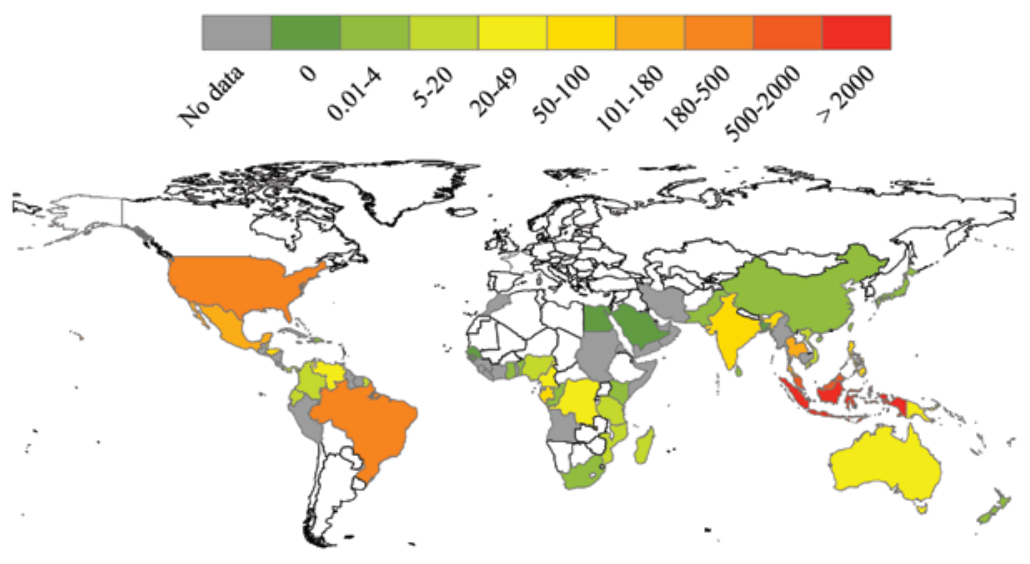

Figure 3 


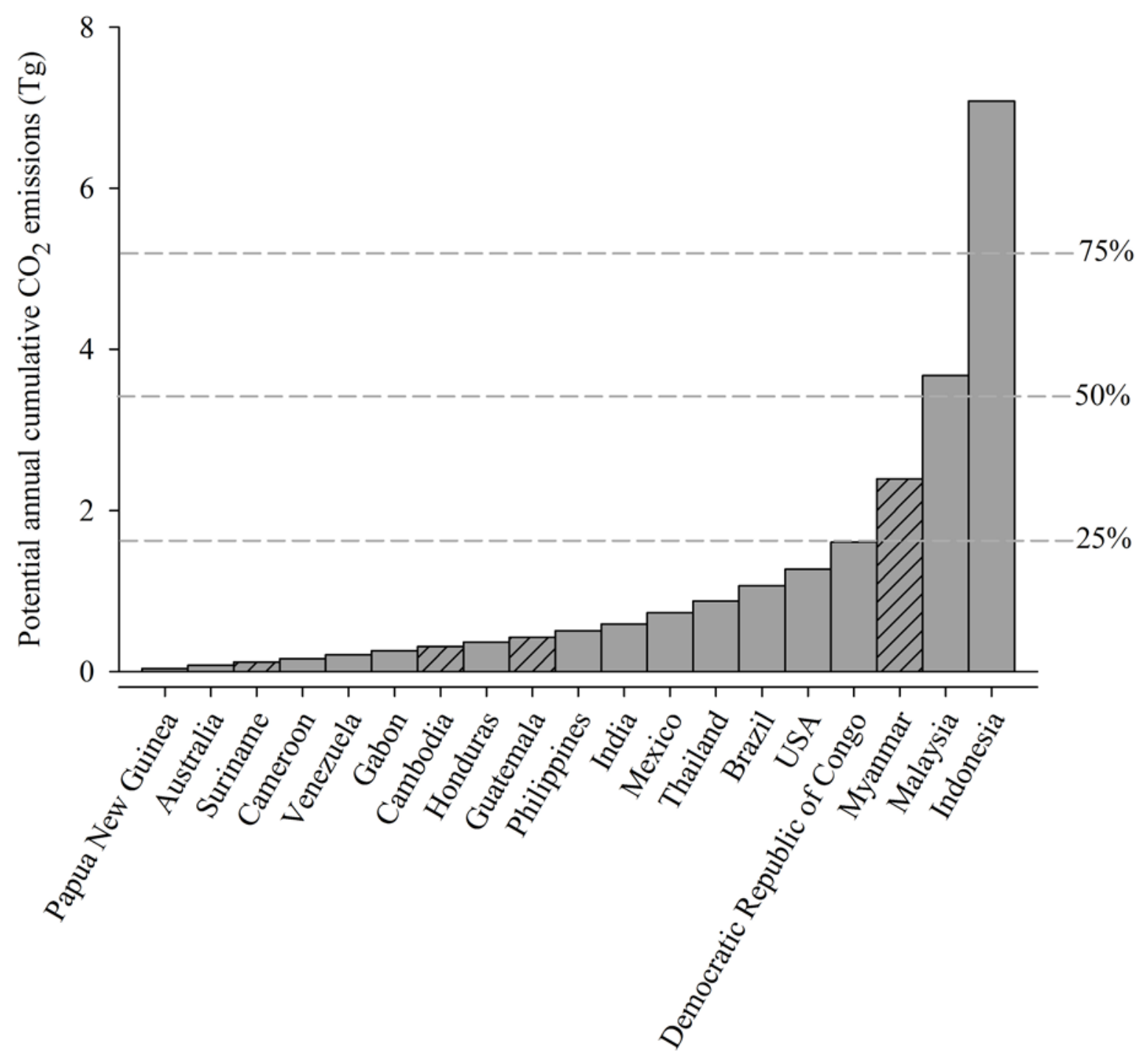

Figure 4 


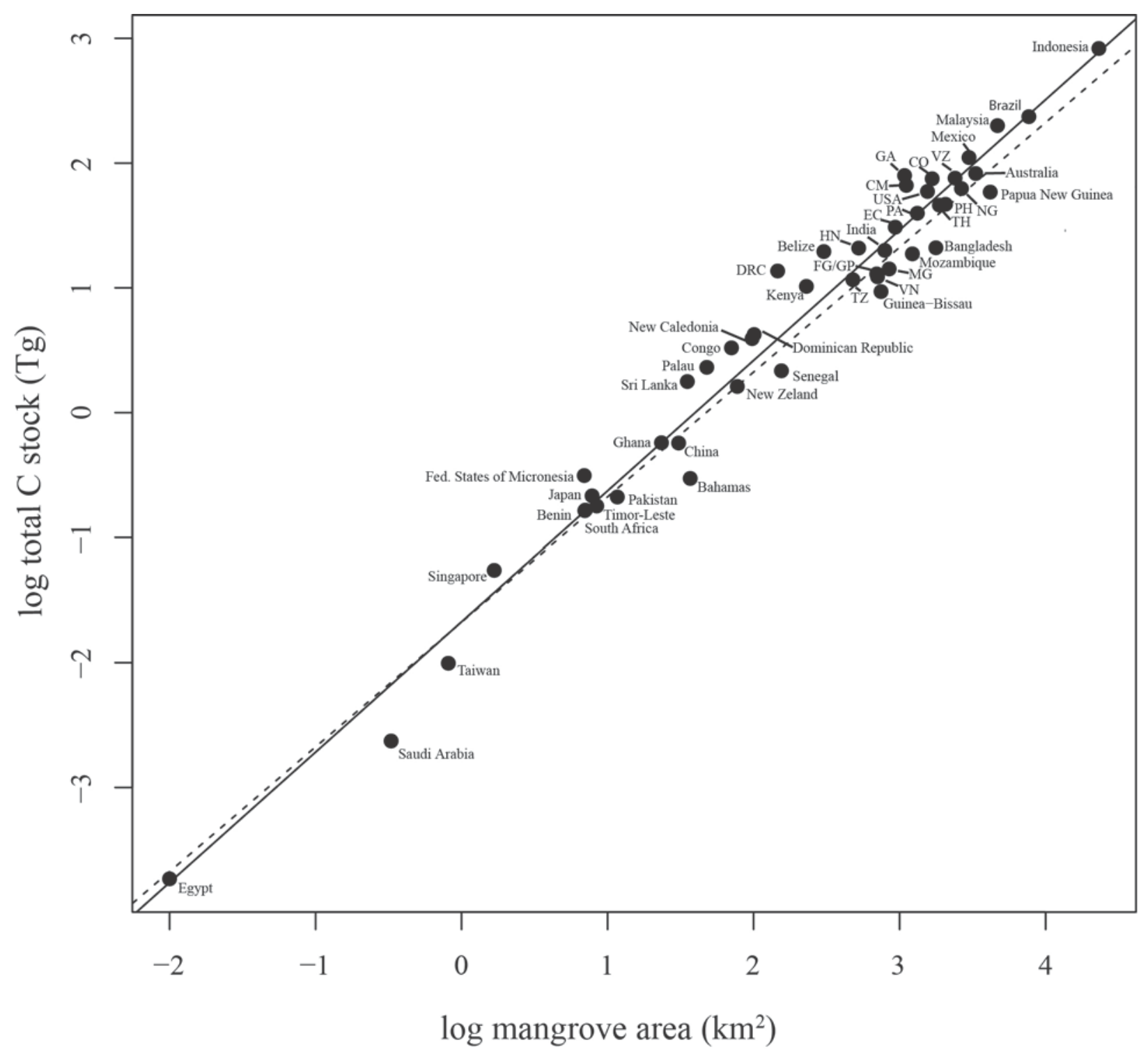

Figure 5 


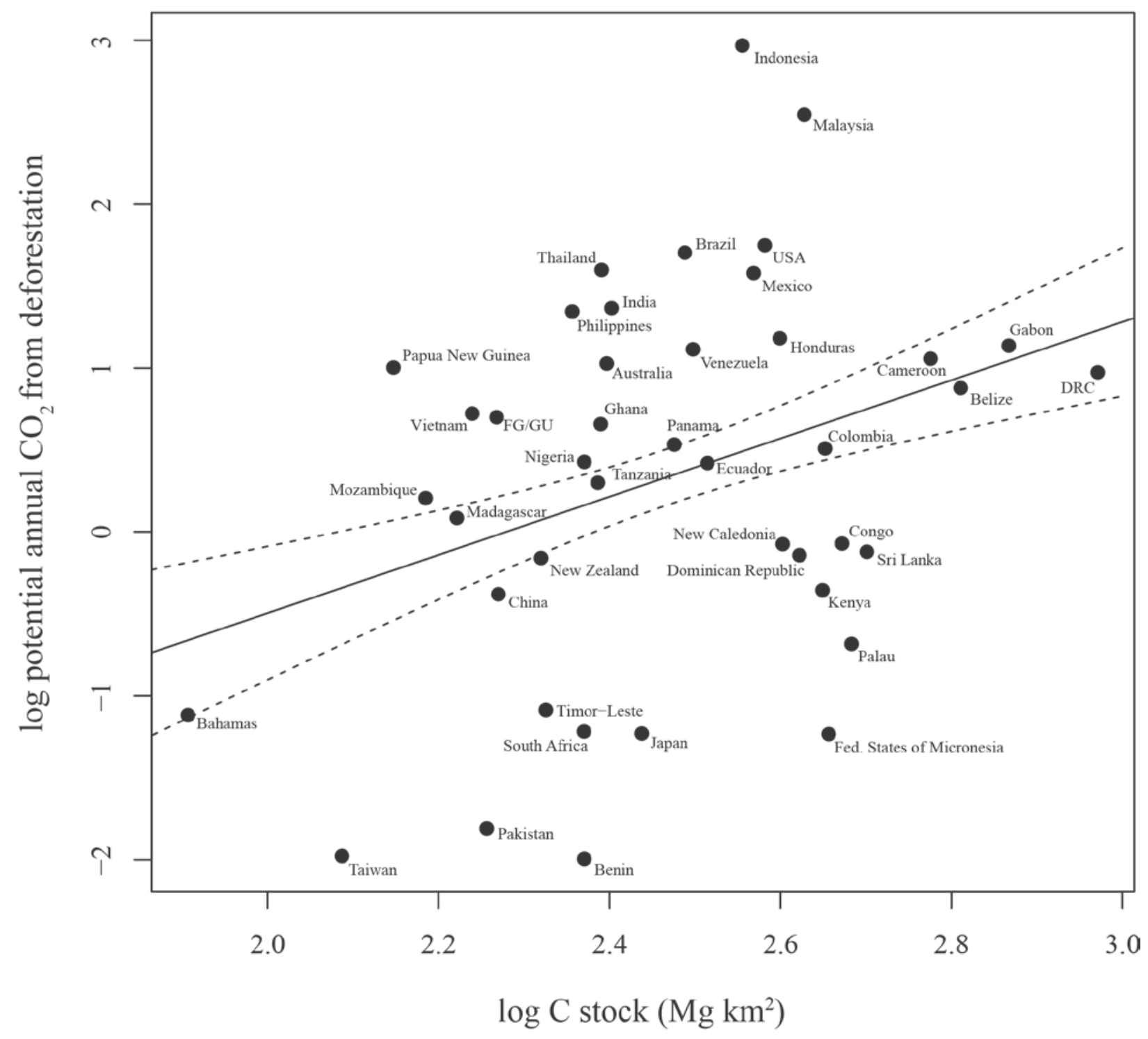

Fig. 6 